\title{
Taş Hastalığında Açık ve Laparoskopik Cerrahinin Yeri Var Mı?
}

\author{
Selçuk Şahin ${ }^{1}$, Volkan Tuğcu ${ }^{1}$
}

${ }^{1}$ Bakırköy Sadi Konuk Eğitim ve Araştırma Hastanesi, Üroloji Kliniği, İstanbul

Uims

riner sistem taş hastalığı, üroloji pratiğinde en sık rastlanılan hastalıklardan birisidir. Siklığ 1 coğrafi, ırk, diyet ve genetik faktörlere bağlı olarak değişir. Çeşitli çalışmalarda sıklığı \%1-20 arasında, nüks oranı 5-10 yıl için \%50, 20 yıl için ise \%75 olarak bildirilmiştir (1). Çapı $4 \mathrm{~mm}$ 'in altında olan taşların \%95'i kendiliğinden düşmekteyken, 10 mm'den büyük taşlarda bu oran çok azdır (2). Üriner sistem taş hastalığında lokalizasyon sıklıkla böbrek olup, bunların büyük bir kısmına müdahale gerekmektedir.

Taş cerrahisi tıbbın çok eski zamanlarından beri bilinen alanlarından biridir. Milattan önce dahi mesane taşları için açık cerrahi veya üretral taş çıkarma işlemleri yapılmaktaydı. Son 30 yıla kadar neredeyse bütün taşlar için açık cerrahi uygulanırken, teknolojideki gelişmeler tedavi şeklini neredeyse tamamen değiştirmiştir. Özellikle 1980'lerde böbrek taşlarının tedavisinde ekstrakorporeal şok dalga litotripsi (SWL) ve perkütan nefrolitotominin (PNL) uygulanmaya başlamasıyla açık taş cerrahisinin kullanımı dramatik bir şekilde azalmıştır (3). Ancak daha sonraları bütün taşların SWL ile kırılamayacağı, taş yüküne ve cinsine göre sınırlamalar getirilmesi gerektiği anlaşılmıştır. Buna rağmen, endoüroloji alanındaki gelişmeler açık taş cerrahisinin tekrar popüler hale gelmesini engellemiştir. Teknolojinin ürünleri olan küçük semirijid ve fleksibl üreterorenoskoplar, taş kırma (ultrasonik, elektrohidrolik, lazer) cihazlarının ve floroskopinin gelişimi sayesinde üreteroskopik litotripsi endikasyonları genişlemiştir. Günümüzde, taş hastalığının cerrahi tedavisinde, gelişmiş ülkelerde vakaların yaklaşık olarak \%1.5'i için açı cerrahiye ihtiyaç duyulurken, bu oranın gelişmekte olan ülkelerde \%26'dan \%3.5'e düştüğü bildirilmektedir $(4,5)$.

Son yıllarda teknolojinin gelişimine paralel olarak laparoskopik cerrahi üroloji pratiğinde yaygın olarak kullanılır hale gelmiştir. Laparoskopik taş cerrahisi de açık cerrahi girişimlere minimal invaziv bir alternatif olabilmektedir. Laparoskopik cerrahi, 2007 Avrupa Üroloji Derneği (EAU) kılavuzlarında bir "seçenek iken", 2009'da "yüksek öneri" seviyesinde, 2014 yılında ise öneri düzeyi " $C$ " olarak açık cerrahinin üzerinde kılavuzlarda yerini almıştır (6). Günümüzde, üriner sistem taş hastalığında laparoskopi, böbrek ve üreterin taş yükünün fazla olduğu, SWL ve/veya endoürolojik girişimlerin yetersizliği, anatomik anomali ve obezite gibi belli durumlarda önerilmektedir.

Bu makalede üriner sistem taş hastalığında açık ve laparoskopik cerrahinin endikasyonları, uygulanan teknikler ve güncel durumu literatür ve kılavuzlar eşliğinde gözden geçirilecektir.

\section{Böbrek Taşları}

Böbrek taşı cerrahisinde kılavuzların önerileri sürekli değişkenlik göstermektedir. Günümüzde $2 \mathrm{~cm}^{\prime}$ den küçük böbrek taşları için; SWL ve RIRS ilk tercihken, $2 \mathrm{~cm}$ 'den büyük böbrek taşları için birinci seçenek PNL olup bunu SWL ve RIRS takip etmektedir. Son 10 yılda endoürolojide muazzam bir gelişme izlenmiştir. Gelişen teknoloji ile birlikte fleksibl ureterorenoskoplar daha da geliştirilmiş, digital görüntü sistemleri kullanılmaya başlanmıştır. $\mathrm{Bu}$ sebeple kılavuzlarda son y1llarda retrograd intrarenal cerrahinin böbrek taşı tedavisinde önceliği artmıştır. Bu teknolojinin en önemli dezavantajı maliyetinin yüksek olması gibi görünmektedir.

SWL ya da endoürolojik girişimlerin başarısız veya yetersiz olduğu hastalarda, at nalı, ektopik veya rotasyone böbreklerdeki büyük taşlarda, soliter büyük pelvisli böbrek ya da anterior taşlı kaliks divertikülü gibi özellikli durumlarda açık veya laparoskopik cerrahi önerilmektedir.

Açık ameliyat uygulamasında böbrek taşlarına yaklaşım değişik şekillerde yapılabilmektedir. 1879'da Heinke tarafından tanımlanan pyelolitotomi, uzun yıllar en sik uygulanan taş ameliyatı olmuştur (7). Taş cerrahilerinin amacı böbreği taştan tamamen temizlemek, en az parankim kaybına neden olmak, en az istenmeyen yan etki oranı elde etmek ve taş tekrarını önlemektir. Güncel yayınlarda açık cerrahiyi öneren yazarların dayandığı temel konu, açık cerrahinin taşsızlık oranı bakımından minimal invaziv tedavilere göre üstünlüğüdür $(8,9)$. Ancak daha kısa iyileşme süresi, daha kısa hastanede kalış ve daha az postoperatif ağrı minimal invaziv tedavileri ön plana çıkarmaktadır. Yakın tarihli bir seride açık cerrahi seçiminin, \%55'inde taş yükü fazlalığı, \%29'unda minimal invaziv tedavilerin başarısızlığı, \%24'ünde anatomik anomaliler, \%10'unda morbid obezite ve \%7'sinde eşlik eden hastalıkların rol oynadığı bildirilmiştir (8).

Laparoskopik piyelolitotomi ilk olarak 1994 senesinde Gaur tarafından rapor edilmiştir (10). Birçok çalışmayla etkinliği gösterilmiş, taşsızlık oranı \%71-100 ve açığa dönüş oranı \%0-27 arasında bildirilmiştir (11-13). Gaur'un retroperitoneal boşlukta balon dilatasyonunu bulması ürolojik laparoskopinin gelişmesine büyük katkıda bulunmuştur (14) (Resim 1). Böylece böbrek ve üreter taşı cerrahisi güvenli bir şekilde yapılır hale gelmiştir. Üriner sistem taşlarına yönelik transperitoneal yolla yapılan laparoskopik girişimlerin 
enfekte idrarın peritoneal boşluk ve organlarla teması gibi bir riski mevcuttur. Buna karşın transabdominal yolla yapılan girişimlerde herhangi bir önemli komplikasyon gelişmediğini bildiren çalışmalar da mevcuttur $(15,16)$. Transperitoneal yaklaşımla barsak motilitesinin geç kazanıldığı, analjezik ihtiyacının, ileus ve hastanede kalış sürelerinin daha fazla olduğu gösterilmiştir (17). Bununla birlikte transperitoneal yaklaşımın da avantajları vardır. Bu avantajlar, daha geniş alan sağlaması, aşina anatomik noktalar bulunması, atnalı böbreklerde pelvise önden kolay ulaşım ve üreterin alt seviyelerine kadar kolay diseksiyon sağlamasıdır.

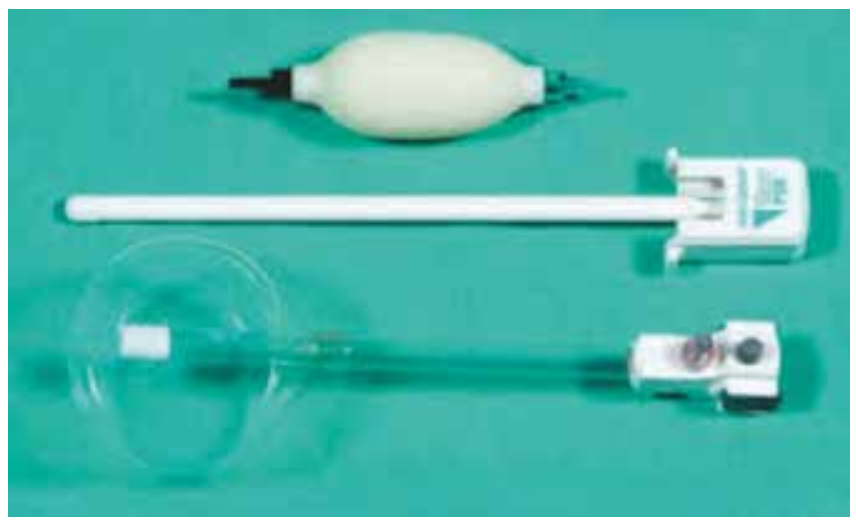

Resim 1: Laparoskopik dilatasyon balonu

Laparoskopik piyelolitotomi ve PNL'yi karşılaştıran en geniş randomize çalışmada iki gruba da $89^{\prime}$ ar hasta dâhil edilmiştir. Hastanede kalış süresi, transfüzyon oranı ve komplikasyonlar iki grup arasında benzer orandayken, laparoskopi grubunda operasyon süresi daha kısa, postoperatif ateş ve hemoglobin düşüşü daha az olarak bulunmuştur. Postoperatif 3. ayda taşsızlık oranı laparoskopi grubunda daha yüksek (\%98-\%90) olarak tespit edilmiştir (18).

Ülkemizde yapılan LP ile PNL'yi karşılaştıran bir çalışmada, PNL grubunda operasyon süresi ve hastanede kalış süresinin daha kısa, LP grubunda ise kan kaybının daha az olduğu, taşsızlık oranlarının ise benzer olduğu gösterilmiştir (19). LP'nin soliter böbrekte PNL ile karşılaştırılmasında, taşsızlık oranları, kan kaybı, hastanede kalış süreleri ve morbidite açısından benzer olduğu ancak operasyon süresinin LP'de daha uzun olduğu gösterilmiştir (20). Otörler, tek seans LP'yi yüksek taşsızlık oranı (\%85-100), kan kaybı ve hematürinin az olması ve nefron koruyucu özelliklerinden dolayı önermektedir. Ancak, LP'de pyelotomi insizyonunun kapatılması için ileri seviyede laparoskopik beceri gerekmektedir ve bunun yokluğunda uzamış idrar kaçağı görülebilir (21-23).

Laparoskopik piyelolitotomi esnasında kaliksiyel taşları çıkarabilmek için çeşitli teknikler geliştirilmiştir. Salvado ve ark.'ları operasyon sırasında laparoskopi portundan fleksibl üreteroskopla girilerek taşların alınabileceğini bildirmişlerdir (Resim 2) (24). Borges ve ark.'ları da; fibrin ve trombin karışımından bir koagülüm sayesinde kaliksiyel taşların temizlenebileceğini bildirmişlerdir (25).

Üreteropelvik darlık cerrahisinde laparoskopik piyeloplastinin artan sıklıkla kullanmasıyla eş zamanlı böbrek taşlarının laparoskopik olarak alınması çok sık uygulanmaktadır. Stein ve ark.'ları 117 hastalık laparoskopik piyeloplasti

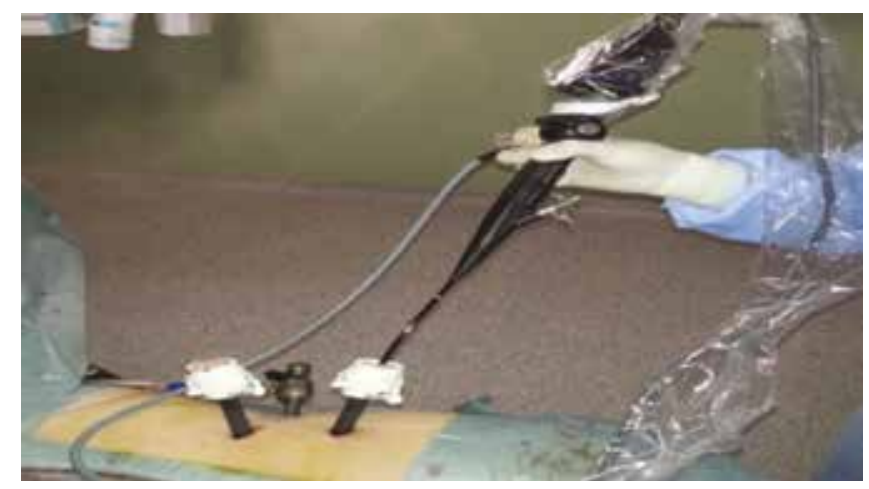

Resim 2: Laparoskopi portundan fleksibl sistoskopla girilerek böbrek kaliks taşlarına girişim

serisinde eş zamanlı böbrek taşlarınının çoğunu laparoskopik grasper yardımıyla, kalan kısmını fleksibl nefroskopla almışlardır (26). Benzer şekilde Srivastava ve Ramakumar, bu prosedürle yüksek başarı bildirmişlerdir $(27,28)$.

Renal pelvisten ulaşılamayacak taşları almak için renal parenkim insizyonu yapılması olarak bilinen anatrofik nefrolitotomi, açık cerrahi olarak özellikle staghorn taşlarda uzun yıllar tercih edilmiştir. Bu prosedür, yüksek taşsızlık oranına rağmen, postoperatif renal fonksiyonda bozulma, yüksek transfüzyon oranı (\%6) ve kanama nedeniyle \%2 reoperasyon oranına sahiptir (29-31). SWL ve PNL'nin kullanıma girmesiyle, bu cerrahiye gereksinim çok azalmıştır. Laparoskopik cerrahideki teknik ilerleme sonucu büyük böbrek taşlarında bu cerrahinin endoskopik olarak yapılabilirliği sorgulanmıştır. Kaouk, ilk başarılı laparoskopik anatrofik nefrolitotomiyi domuz modelinde bildirmiştir (32). Kısa süre sonra Değer ve ark.'ları, insanda bu operasyonun uygulanabilirliğini göstermiştir (33). Fakat bu konuda literatürde karşılaştırmalı çalışma yoktur. Zhou ve ark.'ları, ortalama taş boyutu $52 \mathrm{~mm}$ olan 11 hastada laparoskopik anatrofik nefrolitotomi sonuçlarını yayımlamışlardır. Ortalama sıcak iskemi süresi $31 \mathrm{dk}$ iken, 1 hasta dişında tüm hastalarda tam taş temizliği sağlanmıştır. Üç hastada spontan düzelen idrar kaçağı olmuş, hiçbir hastada kan transfüzyonu gerekli olmamıştır (34). Simforoosh ve ark.'ları 25 vakalık serilerinde yüksek taşsızlık oranına (\%88) karşın, yüksek transfüzyon oranı (\%24) ve biri nefrektomi olmak üzere \%20 oranında Clavien 3 ve üzeri komplikasyon bildirmişlerdir. Otörler yüksek başarı oranına rağmen bu prosedürün sadece deneyimli laparoskopik cerrahlar tarafından seçilmiş vakalarda yapılabileceğini ifade etmişlerdir (35).

Anomalili böbreklerdeki taşlar: Atnalı böbrek anamolisi en yaygın füzyon anomalisi olup, üreterin pelvise yüksek girmesi, üriner staz gibi faktörlere bağlı olarak taş oluşma riski \%20-60 oranında değişmektedir. Küçük taşlarda SWL ve RIRS'ın başarısı yüksek olmasına karşın; büyük taşlarda ilk tercih PNL'dir. Bununla birlikte büyük pelvis taşlarında laparoskopik pyelolitotomi alternatif bir tedavi seçimi olabilmektedir (36-38).

Laparoskopi, anomalili böbreklerde hem tek başına; hem de diğer endoskopik yön-temlere yardımcı olarak kullanılmaktadır. Toplayıcı sistem yapısının uygun olmadığı, taşların derinde olduğu ve hemen arkasında önemli vaskuler yapıları içerdiği için; istmik yerleşimli kaliks taşlarında perkutan giriş ciddi risk taşımakta ve bu nedenle laparoskopi tercih edilebilmektedir (39). Ayrıca atnalı böbrekte renal pel- 
vis taşına eşlik eden UP darlıklarda da laparoskopik tedavi uygulanmaktadır (36).

Çapraz füzyon ektopisi olan hastalarda taş tedavisinde PNL girişi anatominin kompleks bir hal alması nedeniyle sıkıntılı olup tomografi rehberliğinde yapılabilmektedir. Çapraz füzyon ektopili taşlı böbrekte laparoskopik pyeloplasti ve pyelotomi girişimlerinin başarıyla sonuçlandığını gösteren olgu serileri bildirilmiştir (36-38).

Ektopik pelvik böbreğin taş cerrahisinde laparoskopi yardımlı PNL güvenli girişi sağlamak için yaygın olarak uygulanmaktadır. Bunun yanı sıra tek başına LP, ektopik pelvik böbrekte büyük pelvis taşları için alternatif tedavi seçeneği olabilmektedir. İlk defa Eshghi ve ark.'ları taşlı pelvik ektopik böbreğe laparoskopi eşliğinde PNL uygulamışlardır (39). Sonraki yıllarda çok sayıda laparoskopi yardımlı PNL yapılan taşlı pelvik böbrekli olgu bildirilmiştir $(41,42)$. Bu kompleks anatomiye, taşa yönelik girişimin yanı sıra laparoskopik pyeloplastinin yapıldığı olgular eklenmiştir (43). Renal pelvisin laparoskopik mobilizasyonu bu işlemlerde kritik öneme sahiptir. Sağ taraf yerleşimli böbreklerde böbrek önünde seyreden kolon segmentinin laparoskopik olarak uzaklaştırılması, sol taraf yerleşimli böbreklerde ise transmezokolik yaklaşım yeterli ve güvenli girişim sağlamaktadır (35).

\section{Kaliks Divertikülü Taşları}

Kaliks divertikülü taşlarında PNL ve fleksibl URS'nin etkinliği ve başarısı kanıtlanmış olmasına rağmen, bu yöntemlerin yetersiz olduğu anterior yerleşimli, ince duvarlı divertiküllerde laparoskopi önerilebilmektedir (44). Anterior yerleşimli divertiküllere perkutan yaklaşım zor olabileceğinden transperitoneal laparoskopik yaklaşım daha uygun gibi görünmektedir (45). Laparoskopik transperitoneal ve retroperitoneal yaklaşımların hem anterior hem de posterior kaliks divertiküllerinde çok iyi sonuçlar verdiği bildirilmiştir $(36,45)$. Laparoskopik olarak taş çıkarıldıktan sonra divertikül duvarı eksize edilmekte, takiben kalan divertikül yüzeyi argon ya da koter ile ablate edilmektedir.

\section{Üreter Taşları}

Son 30 senede üreter taşı tedavisinde büyük ilerlemeler olmuştur. Şok dalga tedavisi (SWL), üreterorenoskopi ve perkütan girişimlerdeki gelişmeler sonucu tedavide minimal invaziv girişimler büyük oranda açık cerrahinin yerini almıştır (46). Günümüzde açık cerrahi kompleks vakalarda ve diğer tedavi yöntemlerinin başarısız olduğu durumlarda önerilmektedir (47).

SWL'nin avantajları, anestezi gereksinimi olmaması ve minimal invaziv bir işlem olmasıdır. Buna karşın, büyük $(>1.5 \mathrm{~cm})$ ve sert taşlarda başarısı düşüktür (48) Fleksibl aletler ile birlikte holmium lazerin kullanılmasıyla üreterorenoskopinin başarı oranı \%98 olarak saptanmıştır (49). Fakat özellikle gelişmekte olan ülkelerde bu tekniğin maliyeti önemli bir dezavantajdır (50). Üreteroskopik prosedürlerde impakte taşları olan hastalarda, ödem ve darlığa bağlı olarak taşa ulaşılamaması önemli bir başarısızlık nedenidir (51).

Günümüzde laparoskopik taş cerrahisinde en sık kullanılan yöntem olan üreterolitotomi ilk kez Wickham tarafından 1979'da tanımlanmıştır (52). Birçok klinik seride laparoskopinin uygulanabilirliği gösterilmiştir. Laparoskopik üreterolitotominin en önemli üstünlüğü tek seansta ek girişim gereksinimi olmaksızın yüksek başarı sağlamasıdır. Bu tek- nikle tek seansta \%95'in üzerinde başarı saptanmıştır (53). Açık cerrahi ile karşılaştırıldığında benzer başarı oranlarına ilaveten analjezik gereksinimi, hastanede kalış süresi, iyileşme süresi ve kozmetik açılardan daha iyi bulunmuştur. Komplikasyonlar açısından fark saptanmamıştır (54).

Ko ve ark.'ları, taş boyutu $1.5 \mathrm{~cm}$ 'nin üstünde olan hastalarda laparoskopik üreterolitotomi ile üreteroskopik litotripsiyi karşılaştırmışlardır. Tek prosedür sonucu taşsızlık oranı laparoskopi grubunda daha yüksek (\%100-77) olarak bulunmuştur. Laparoskopik üreterolitotominin düşük komplikasyon riski ile primer tedavi modalitesi olarak kullanılabileceğini bildirmişlerdir (55). Fang ve ark.'ları 50 hastayı içeren çalışmalarında laparoskopik üreterolitotomi ile üreteroskopik holmium lazer litotripsiyi karşılaştırmışlar ve laparoskopi grubunda daha yüksek taşsızlık oranı ve kısa operasyon süresi tespit etmişlerdir (56). Neto ve ark.'ları, prospektif çalışmalarında $1 \mathrm{~cm}$ 'den büyük taşı olan hastalarda SWL, LU ve URS' yi karşılaştırmışlar ve laparoskopi grubunda taşsızlık oranını (\%93) URS (\%62) ve SWL (\%35)'ye göre daha yüksek olarak saptamışlardır $(57,58)$.

Laparoskopik üreterolitotomi transperitoneal veya retroperitoneal yoldan uygulanabilir $(59,60)$ (Resim 3). Bove ve ark.'ları üst üreter taşı tedavisinde iki yöntemi karşılaştıran ilk prospektif non-randomize çalışmayı yapmışlardır. İki grubun sonuçlarını karşılaştırdıklarında iki tekniği benzer olarak rapor etmişlerse de; toplam operasyon süresi, operasyon alanına girişe kadar geçen süre ve üreter dikilmesi için gerekli süre transperitoneal grupta daha kısa olarak bulunmuştur (61). Singh ve ark.'ları orta ve üst üreter taşı olan hastalarda iki yöntemi karşılaştıran ilk prospektif randomize çalışmayı yapmışlardır. Total operasyon süresi ve intrakorporeal sütür süresi bakımından iki grup arasında anlamlı fark bulunmamıştır. Postoperatif ağrı skoru ve taştan temizlenme oranı iki grup arasında benzer olarak rapor edilmesine karşın, morbidite ve hastanede kalış süresi transperitoneal grupta daha yüksek olarak bildirilmiştir $(62,63)$.

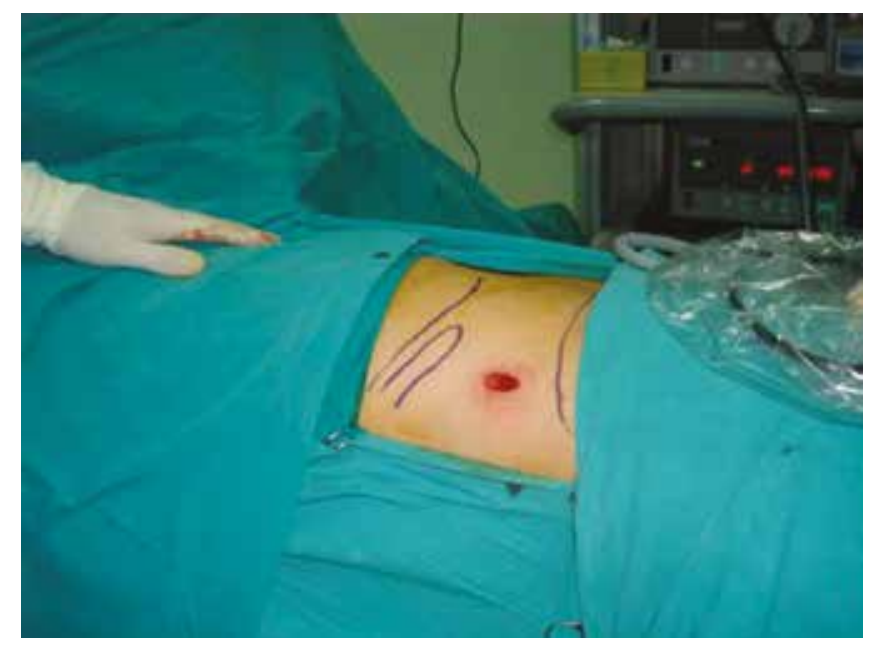

Resim 3: Laparoskopik retroperitoneal üreterolitotomide hasta pozisyonu ve port lokalizasyonunun belirlenmesi

Laparoskopik üreterolitotominin yüksek başarı oranı ile birlikte komplikasyon oranı da düşüktür. Birçok çalışmada komplikasyon oranı \%0 olarak bildirilirken, en yüksek seride \%17.6 bildirilmiştir (64-66). En sık ve önemli komplikasyonları taşın migrasyonu, idrar kaçağı ve üreter darlığıdır. 
Günümüzde laparoskopik üreterolitotominin endikasyonu sınırlıdır. Açık cerrahiye alternatif olarak; diğer tedavilerin başarısızlığında, anatomik anomaliler varlığında, aynı zamanlı başka cerrahi girişimler gerektiğinde ve büyük, impakte üst üreter taşlarında önerilir (Resim 4). Üreter taşı tedavisinde SWL ve URS ilk tercihlerdir (5).

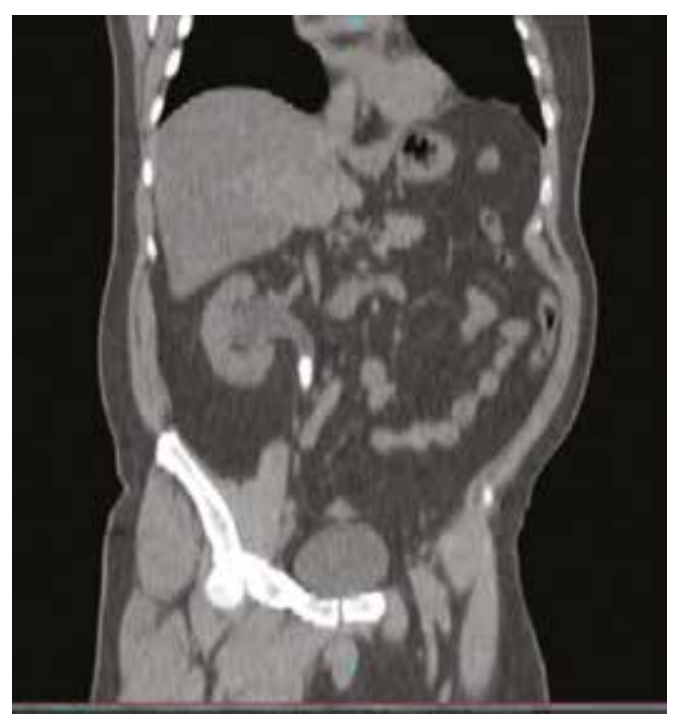

Resim 4: Kliniğimizde laparoskopik üreterolitotomi yapılan sağ üreterinde $22 \mathrm{~mm}$ taşı olan hastanın BT görüntüsü

\section{Mesane Taşı}

Günümüzde mesane taşlarının büyük kısmı transuretral yoldan tedavi edilmektedir. Büyük taşlarda ise perkütan yöntemler tercih edilir (67). Açık cerrahinin kullanımı çok azalmıştır.

Son y1llarda laparoskopinin mesane taşlarının tedavisinde kullanımı da gündeme gelmiştir. Batislam ve ark.'ları, çapı 3 cm'ye kadar olan mesane taşlarını video-sistoskopik kontrol altında perkütan yolla çıkartmak için laparoskopik grasper ve torba gibi aletlerden faydalanmışlardır (68). Miller ve ark.'ları ise, ogmentasyon uygulanmış mesanelerde, endoskopik kontrol altında perkütan olarak yerleştirdikleri 10 mm'lik trokardan laparoskopik torbayı mesaneye yollayarak dört hastanın üçünde taşların tümünü bunun içine alıp çıkartmayı başarmışlardır (69). Çok ender görülen urakus taşlarında da laparoskopi faydalı olabilir (70).

\section{Sonuç}

Teknolojideki ilerlemeler sayesinde ülkemizde de açık taş cerrahisi kullanımı çok azalmıştır. Üniversiteler ve eğitim hastanelerinde minimal invaziv tedavilerin yoğun şekilde uygulanması sonucu yeni mezun üroloji uzmanları prosedürleri uygulayabilmektedir. Ayrıca derneklerin uzmanlara yönelik eğitim kursları sayesinde bu yöntemler ülkemizde sıklıkla kullanılmaktadır. Fakat üroloji uzmanlarının endoürolojik tedavilerin yetersiz kaldığı durumlarda ve seçilmiş hastalarda laparoskopik ve açı taş cerrahilerini uygulayabilecek tecrübelerinin de olması gerekmektedir.

\section{Kaynaklar}

1. Trinchieri A CG KS, Jun Wu K. Epidemiology. In: Stone Disease. C.P. Segura JW KS, Pak CY, Preminger GM, Tolley D., eds. Health Publications, Paris. 2003. p. 13-30.

2. Preminger GM, Tiselius HG, Assimos DG, et al; EAU/ AUA Nephrolithiasis Guideline Panel. Guidelines on urolithiasis. J Urol 2007 Dec;178(6):2418-34.

3. Tiselius HG, Alken P, Buck C, Galluci M, Knoll T, Sarica K, Türk C. Guidelines on urolithiasis, European Association of Urology, 2008.

4. Hruza M, Schulze M, Teber D, Gozen AS, Rassweiler JJ. Laparoscopic techniques for removal of renal and ureteral calculi. J Endourology 2009, 23(10):1713-1718.

5. Turk C, Knoll T, Petrik A, Sarica K, Skolarikos A, Straub M, Seitz C. European Association of Urology, Guidelines on urolithiasis, 2015.

6. Simforoosh N, Aminsharifi A. Laparoscopic management in stone disease. Curr Opin Urol 2013, 23(2):169-174.

7. Wershub LP. Urology, from antiquity to the $20^{\text {th }}$ century. St Louis (MO): WH Green; 1970.

8. Paik ML, Wainstein MA, Spirnak JP, Hampel N, Resnick MI. Current indications for open stone surgery in the treatment of renal and ureteral calculi. J Urol 1998;159(2):374-9.

9. Matlaga BR, Assimos DG. Changing indications of open stone surgery. Urology 2002; 59(4):490-4.

10. Gaur DD, et al. Retroperitoneal laparoscopic pyelolithotomy. J. Urol 1994; 151, 927-929.

11. Humphreys MR. The emerging role of robotics and laparoscopy in stone disease. Urol Clin North Am 2013; 40, 115-128.

12. Nambirajan T, et al. Role of laparoscopy in management of renal stones: single-center experience and review of literature. J Endourol 2005; 19: 353-399.

13. Hemal AK, et al. Evaluation of laparoscopic retroperitoneal surgery in urinary stone disease. J. Endourol 2001; 15: 701-705

14. Gaur DD. Laparoscopic operative retroperitoneoscopy: use of a new device. J Urol 1992; 148(4):1137- 1139.

15. Abuanz S, Game X, Roche JB, Guillotreau J, Mouzin M, Sallusto F, Chaabane W, Malavaud B, Rischmann P. Laparoscopic pyeloplasty: comparison between retroperitoneoscopic and transperitoneal approach. Urology 2010, 76(4):877-881.

16. Nambirajan T, Jeschke $S$, Albqami N, Abukora F, Leeb $\mathrm{K}$, Janetschek G. Role of laparoscopy in management of renal stones: single-center experience and review of literature. J Endourol 2005; 19(3):353-359.

17. Singh V, Sinha RJ, Gupta DK, Kumar M, Akhtar A. Transperitoneal versus retroperitoneal laparoscopic ureterolithotomy: a prospective randomized comparison study. J Urol 2013, 189(3):940-945.

18. Li S, et al. Randomized controlled trial comparing retroperitoneal laparoscopic pyelolithotomy versus percutaneous nephrolithotomy for the treatment of large renal pelvic calculi: a pilot study. J. Endourol 2014; 28, 946-950.

19. Tefekli A, Tepeler A, Akman T, Akcay M, Baykal M, Karadag MA, Muslumanoglu AY, de la Rosette J. The comparison of laparoscopic pyelolithotomy and percutaneous nephrolithotomy in the treatment of solitary large renal pelvic stones. Urol Res 2012, 40(5):549-555. 
20. Al-Hunayan A, Khalil M, Hassabo M, Hanafi A, AbdulHalim $\mathrm{H}$. Management of solitary renal pelvic stone: laparoscopic retroperitoneal pyelolithotomy versus percutaneous nephrolithotomy. J Endourol 2011; 25(6):975-978.

21. Salvado JA, Guzman S, Trucco CA, Parra CA. Laparoscopic pyelolithotomy: optimizing surgical technique. J Endourology 2009; 23(4):575-578.

22. Kijvikai K. The role of laparoscopic surgery for renal calculi management. Ther Adv Urol 2011, 3(1):13-18.

23. Nouralizadeh A, Simforoosh N, Soltani $\mathrm{MH}$, Sarhangnejad R, Ardestanizadeh A, Shabaninia S, Ziaee SA. Laparoscopic transperitoneal pyelolithotomy for management of staghorn renal calculi. Journal of laparoendosc Adv Surg Tech A 2012; 22(1):61-65.

24. Salvado JA, et al. Laparoscopic pyelolithotomy: optimizing surgical technique. J. Endourol 2009; 23, 575-578.

25. Borges R, et al. Coagulum pyelolithotomy "revisited" by laparoscopy: technique modification. Urology 2012; 79: 1412.e5-1412.e8.

26. Stein RJ et al. Laparoscopic pyeloplasty with concomitant pyelolithotomy: technique and outcomes. J Endourol 2008; 22, 1251-1255.

27. Srivastava A, et al. Laparoscopic pyeloplasty with concomitant pyelolithotomy - is it an effective mode of treatment? Urol Int 2008; 80, 306-309.

28. Ramakumar S, et al. Laparoscopic pyeloplasty with concomitant pyelolithotomy. J Urol 2002; 167, 1378-1380.

29. Assimos DG, et al. Postoperative anatrophic nephrolithotomy bleeding. J Urol 1986; 135, 1153-1156.

30. Assimos DG. Anatrophic nephrolithotomy. Urology 2001; 57, 161-165.

31. WoodhouseCR, et al. The place of extended pyelolithotomy (Gil-Vernet Operation) in the management of renal staghorn calculi. Br. J. Urol. 53, 520-523 (1981).

32. KaoukJH, etal. Laparoscopic anatrophic nephrolithotomy: feasibility study in a chronic porcine model. J Urol 2003; 169, 691-696.

33. Deger $S$, et al. Laparoscopic anatrophic nephrolithotomy. Scand J Urol Nephrol 2004: 38, 263-265.

34. Zhou L, et al. Retroperitoneal laparoscopic anatrophic nephrolithotomy for large staghorn calculi. Int J Urol 2011; 18: 126-129.

35. Simforoosh N, et al. Laparoscopic anatrophic nephrolithotomy for management of staghorn renal calculi. J Laparoendosc Adv Surg Tech A 2013; 23, 306310 .

36. Nadu A, Schatloff O, Morag R, Ramon J, Winkler H. Laparoscopic surgery for renal stones: is it indicated in the modern endourology era? International braz $\mathrm{j}$ urol: official journal of the Brazilian Society of Urology 2009; 35(1): 9-17.

37. Symons SJ, Ramachandran A, Kurien A, Baiysha R, Desai MR. Urolithiasis in the horseshoe kidney: a single-centre experience. BJU international 2008; 102(11):1676-1680.

38. Modi P, Goel R, Dodia S. Case report: laparoscopic pyeloplasty with pyelolithotomy in crossed fused ectopia. J Endourol 2006; 20(3):191-193.

39. Binbay M. Üriner Sistem Taş Hastalığının Tedavisinde Laparoskopik Cerrahi. Turkiye Klinikleri J Urology; 2009, 2 (Special Topics):77-83.
40. Eshghi AM, Roth JS, Smith AD. Percutaneous transperitoneal approach to a pelvic kidney for endourological removal of staghorn calculus. J Urology 1985; 134(3):525-527.

41. Holman E, Toth C. Laparoscopically assisted percutaneous transperitoneal nephrolithotomy in pelvic dystopic kidneys: experience in 15 successful cases. J Laparoendosc Adv Surg Tech A 1998, 8(6): 431-435.

42. Maheshwari PN, Bhandarkar DS, Andankar MG, Shah RS. Laparoscopically guided transperitoneal percutaneous nephrolithotomy for calculi in pelvic ectopic kidneys. Surgical Endosc 2004, 18(7):1151.

43. Elbahnasy AM, Elbendary MA, Radwan MA, Elashry OM, Taha MR. Laparoscopic pyelolithotomy in selected patients with ectopic pelvic kidney: a feasible minimally invasive treatment option. J Endourology 2011; 25(6):985989.

44. Miller SD, Ng CS, Streem SB, Gill IS. Laparoscopic management of caliceal diverticular calculi. J Urol 2002, 167(3):1248-1252.

45. Waxman SW, Winfield HN. Laparoscopic management of caliceal diverticulum. J of Endourol 2009; 23(10):17311732.

46. Paik ML, Wainstein MA, Spirnak JP, et al. Current indications for open stone surgery in the treatment of renal and ureteral calculi. J Urol 1998;159:374-378.

47. Preminger GM, Tiselius HG, Assimos DG, et al. American Urological Association Education and Research, Inc.; European Association of Urology. Guideline for the management of ureteral calculi. Eur Urol 2007;52:1610 1631.

48. Lee YH, Tsai JY, Jiaan BP, Wu T, Yu CC. Prospective ran- domized trial comparing shock wave lithotripsy and ureteroscopic lithotripsy for management of large upper third ureteral stones. Urology 2006;67:480-484.

49. Muslumanoglu AY, Karadag MA, Tefekli AH, et al. When is open ureterolithotomy indicated for the treatment of ureteral stones? Int J Urol 2006;13:1385-1388.

50. Hammady A, Gamal WM, Zaki M, Hussein M, Abuzeid A. Evaluation of ureteral stent placement after retroperitoneal laparoscopic ureterolithotomy for upper ureteral stone: randomized controlled study. J Endourol. 2011; 25(5):825-30.

51. Mugiya S, Ozono S, Nagata M, et al. Retrograde endoscopic management of ureteral stones more than 2 cm in size. Urology 2006; 67: 1164.

52. Wickham JEA. The surgical treatment of renal lithiasis. In: Wickham JEA, ed. Urinary Calculus Disease. New York: Churchill Livingstone; 1979:145-198.

53. Kijvikai K, Patcharatrakul S. Laparoscopic ureterolithotomy: its role and some controversial technical considerations. Int J Urol 2006;13:206-210.

54. Goel A, Hemal AK. Upper and mid-ureteric stones: a pro- spective unrandomized comparison of retroperitoneoscopic and open ureterolithotomy. BJU Int 2001; 88: 679-682.

55. Ko YH, Kang SG, Park JY, et al. Laparoscopic ureterolithotomy as a primary modality for large proximal ureteral calculi: comparison to rigid ureteroscopic pneumatic lithotripsy. J Laparoendosc Adv Surg Tech . 2011;21:7-13.

56. Fang YQ, Qiu JG, Wang DJ, Zhan HL, Situ J. Comparative 
study on ureteroscopic lithotripsy and laparoscopic ureterolithotomy for treatment of unilateral upper ureteral stones. Acta Cir Bras 2012;27:266-270.

57. Lopes Neto AC, Korkes F, Silva JL II, et al. Prospective randomized study of treatment of large proximal ureteral stones: Extracorporeal shock wave lithotripsy versus ureterolithotripsy versus laparoscopy. J Urol 2012;187:164-168.

58. Tugcu V, Resorlu B, Sahin S, Atar A, Kocakaya R, Eksi M, Tasci AI. Flexible Ureteroscopy versus Retroperitoneal Laparoscopic Ureterolithotomy for the Treatment of Proximal Ureteral Stones $>15 \mathrm{~mm}$ : A Single Surgeon Experience. Urol Int 2016; 96:77-82.

59. Wuernschimmel E, Lipsky H. Laparoscopic treatment of an upper ureteral stone. J Laparoendosc Surg. 1993;3:301307.

60. Gaur DD. Laparoscopic operative retroperitoneoscopy: use of new device. J Urol. 1992;148:1137-1139.

61. Bove P, Micali S, Miano R, et al. Laparoscopic ureterolithotomy: a comparison between the transperitoneal and the retroperitoneal approach during the learning curve. J Endourol. 2009; 23: 953-957.

62. Singh V, Sinha RJ, Gupta DK, Kumar M, Akhtar A. Transperitoneal versus retroperitoneal laparoscopic ureterolithotomy: a prospective randomized comparison study. J Urol. 2013; 189: 940-945.

63. Hammady A, Gamal WM, Zaki M, Hussein M, Abuzeid A. Evaluation of ureteral stent placement after retroperitoneal laparoscopic ureterolithotomy for upper ureteral stone: randomized controlled study. J Endourol. 2011; 25: 825-830.
64. Keeley FX, Gialas I, P1lla1 M, Chrisofos M, Tolley DA. Laparoscopic ureterolithotomy: The Edinburgh experience. BJU Int 1999; 84: 765-769.

65. Gaur DD, Agarwal DK, Purohit KC, Darsha-ne AS, Shah BC. Retroperitoneal laparoscopic ureterolithotomy for multiple upper mid ureteral calculi. J Urol 1994; 151: 1001-1002

66. Kijvikai K, Patcharatrakul S. Laparoscopic ureterolithotomy: its role and some controversial technical considerations. Int J Urol 2006;13:206-210.

67. Segarra J, Palou J, Montlleo M, Salvador J, Vicente J. Hasson's laparoscopic trocar in percutaneous bladder Stone lithotripsy. Int Urol Nephrol 2001; 33: 625-6.

68. Batislam E, Germiyanoglu C, Karabulut A, Berberoglu M, Nuhoglu B, Gulerkaya B, et al. A new application of laparoscopic instruments in percutaneous bladder stone removal. J Laparoendosc Adv Surg 1997;7:241-4.

69. Turk I, Deger S, Roigas J, Fahlenkamp D, Schonberger B, Leoning SA. Laparoscopic ureterolithotomy. Tech Urol 1998; 4: 29-34.

70. Micali S, Moore RG, Averch TD, Adams JB, Kavoussi LR. The role of laparoscopy in the treatment of renal and ureteral calculi. J Urol 1997;157:463-6.

Yazışma Adresi:

Volkan Tŭgcu,

Bakırköy Sadi Konuk Eğitim ve Araştırma Hastanesi,

Üroloji Kliniğii, İstanbul

Tel: +90 5325510729

e-mail:volkantugcu@yahoo.com 